\title{
Investigation of the possibility of remote detection of gas outlets in the sea using X-band radar
}

\author{
M. V. Smirnova ${ }^{1,2}$, I. A. Kapustin ${ }^{2,3}$, A.V. Ermoshkin ${ }^{2,3}$ \\ ${ }^{1}$ Volga State University of Water Transport, Nizhny Novgorod, 603950, Russia \\ ${ }^{2}$ Lobachevsky State University of Nizhny Novgorod, Nizhny Novgorod, 603950, \\ Russia \\ ${ }^{3}$ Institute of Applied Physics RAS, Nizhny Novgorod, 603950, Russia \\ E-mail: igoninam@yandex.ru
}

\begin{abstract}
This paper describes the results of the field experiment to study the effect of formation of a film slick as a result of gas escaping from the water column and shows the possibility of its detection by radar means of remote sensing. The experiment in the water area of the Gorky reservoir (Russia) using X-band radar Micran MRS-1000 installed on the avantport lighthouse was conducted. The assessment of the size and morphology of the slick spot was performed. The features that make it possible to distinguish a slick formed by an underwater bubble stream from background slicks of natural origin are noted.
\end{abstract}

\section{Introduction}

Gas outlets from the sea occur for various reasons. One of them is the damage of underwater gas pipelines, the length of which is thousands of kilometers in the world. In this regard, continuous monitoring of the technical condition of pipelines, as well as detection and assessment of the volume of leaks in real time, are essential to minimize economic and environmental damage. To monitor the condition of long subsea pipelines, specialized vessels and air fleet are used, which implies high financial costs and discrete observations. Methods for remote detection of gas leaks on land are being actively developed [1]. In addition, there is an oceanological problem related to the study of gas emissions from the seabed (see, for example, [2, 3]). This work is devoted to the study of the possibilities of a remote approach to detecting gas outlet areas on the sea surface, based on a fundamentally different physical manifestation of this phenomenon.

\section{Problem statement}

Currently, a fairly wide list of physical phenomena has been identified that can be used as a basis for remote detection of gas escaping from the water column. This may be a change in the temperature of the water surface [4]; the manifsestation of anomalies in the signal of reverse acoustic scattering in the water column [5]; disturbance of the sea surface by bubble gas plumes [6]; the appearance of areas of increased turbidity as a result of lifting the suspension from the bottom; anomalies of positive contrast on radar images of places where gas bubbles exit to the water surface in a weak wave or calm due to a lower density of water containing bubbles; observation of areas of smoothing of surface wind waves in radar images as a result of generation of internal waves by gas emissions; smoothing of the sea surface due to the appearance of surface currents around the gas outlet area; domed gas emissions; the 
presence of bubbles and cracks in the ice cover, as well as gas plumes in the atmosphere (see [7] and cited literature).

Bubble gas outlets that form the phenomena described above usually have a sufficiently large scale (from a few meters to hundreds of meters or more) and a long time character, which makes it possible to detect them successfully. But accidents on underwater pipelines occur suddenly, and the scale of the gas outlet area on the water surface may be less than 1 meter, while the suspension lift from the bottom may not occur, and the surface velocity of the current around the gas outlet area and the generation of internal waves in this gas stream may be insufficient to detect such gas emission on satellite images.

On the other hand, according to the flotation theory [8,9], gas bubbles rising from the water column bring surfactants dissolved in it to the surface of the water. Therefore, in natural reservoirs where water contains natural surfactants and suspended substances, the process of gas escape from the water column is accompanied by the appearance of a film of surfactants on the water surface [10]. This surfactant film has a number of properties that differ from the properties of the clean water surface [11]. Previously conducted laboratory [12,13] and field [14] studies confirmed the accumulation of surfactant film on the water surface in result of a short (within 15 minutes) action of the bubble stream.

The sea surface is often covered with films of surfactants of biogenic or petroleum origin. They have a fairly large area and, due to the smoothing of short wind waves and the formation of so-called slicks, are clearly distinguishable on radar images $[11,15,16]$. Methods for classifying slicks formed by petroleum products or caused by natural surfactants are being actively developed [17-24]. However, slicks formed by underwater bubble streams have their own differences, which should be taken into account when developing a method for identifying them.

An important distinguishing feature of the slick formed by a film of surfactants carried out by gas bubbles from a damaged underwater gas pipeline will be the relative immobility of the source of surfactants. This means that even if the surfactant spot is strongly pulled by wind and current, one end of the slick, the so-called "head" of the slick, will always be located above the area of the gas leakage the source of surfactants (similarly, [25, 26]).

\section{Description of the experiment}

In this paper, the effect of forming a film slick in result of gas escaping from the water column and the possibility of its detection by radar means of remote sensing were experimentally confirmed. The field experiment was conducted in the water area of the Gorky reservoir. A compressor was installed on the floating laboratory "Geophysicist" (figure 1a) and supplied air to a depth of about 10 meters. The effects of the removal of natural surfactants from the water column and the formation of a film slick were recorded visually, with a camera and using X-band radar (Micran MRS-1000) installed on the avantport lighthouse (figure 1b). The parameters of the current were recorded by the acoustic Doppler current profiler (ADCP) and the wind - by the ultrasonic wind sensor WindSonic installed on the "Geophysicist". The "Geophysicist" scientific boat itself was anchored at some distance from the exit point of the bubble stream.
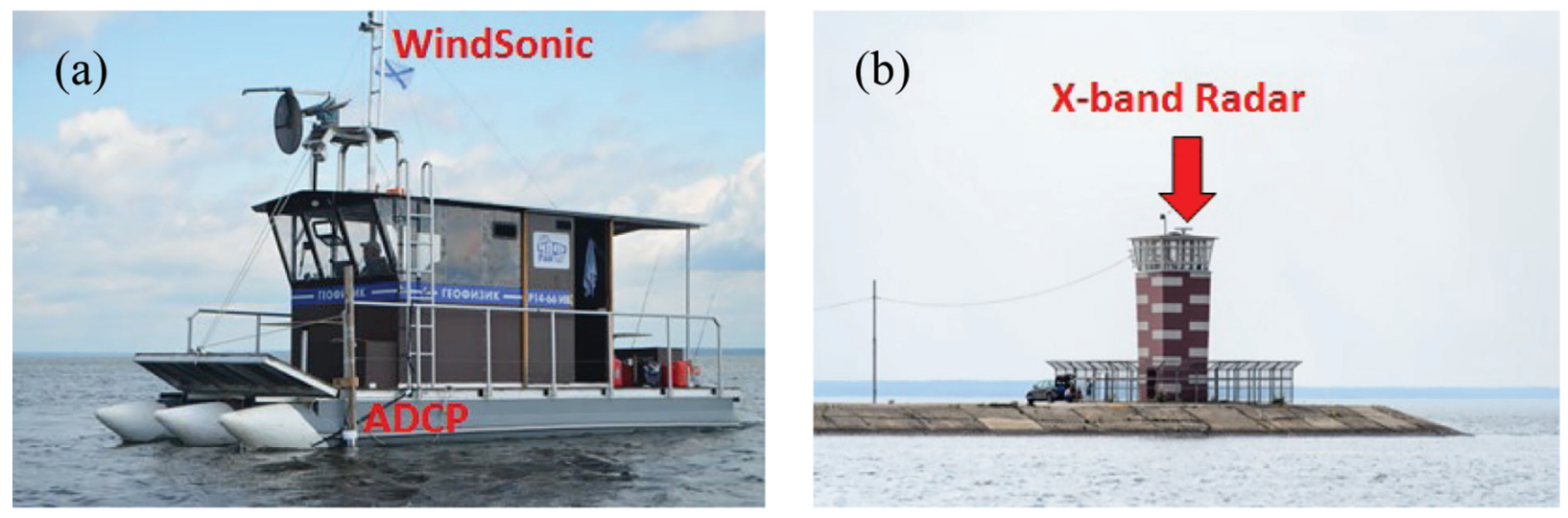

Figure 1. Field experiment on the formation of a film slick by a bubble stream: (a) the scientific boat "Geophysicist", equipped with air compressor, ADCP and ultrasonic wind sensor WindSonic; (b) the avantport lighthouse, where the radar Micran MRS-1000 was located. 


\section{Results and discussion}

The wind speed during the experiment was $3-6 \mathrm{~m} / \mathrm{s}$ from the south. The current in the upper water layer at a depth of 1 meter was stable and its speed was $10 \mathrm{~cm} / \mathrm{s}$ (figure 2), the mean direction of the current vectors was almost due north $\left(8-12^{\circ}\right)$. The slick bands recorded on the radar images (figure 3 ) were oriented in the direction of the total surface current vector.

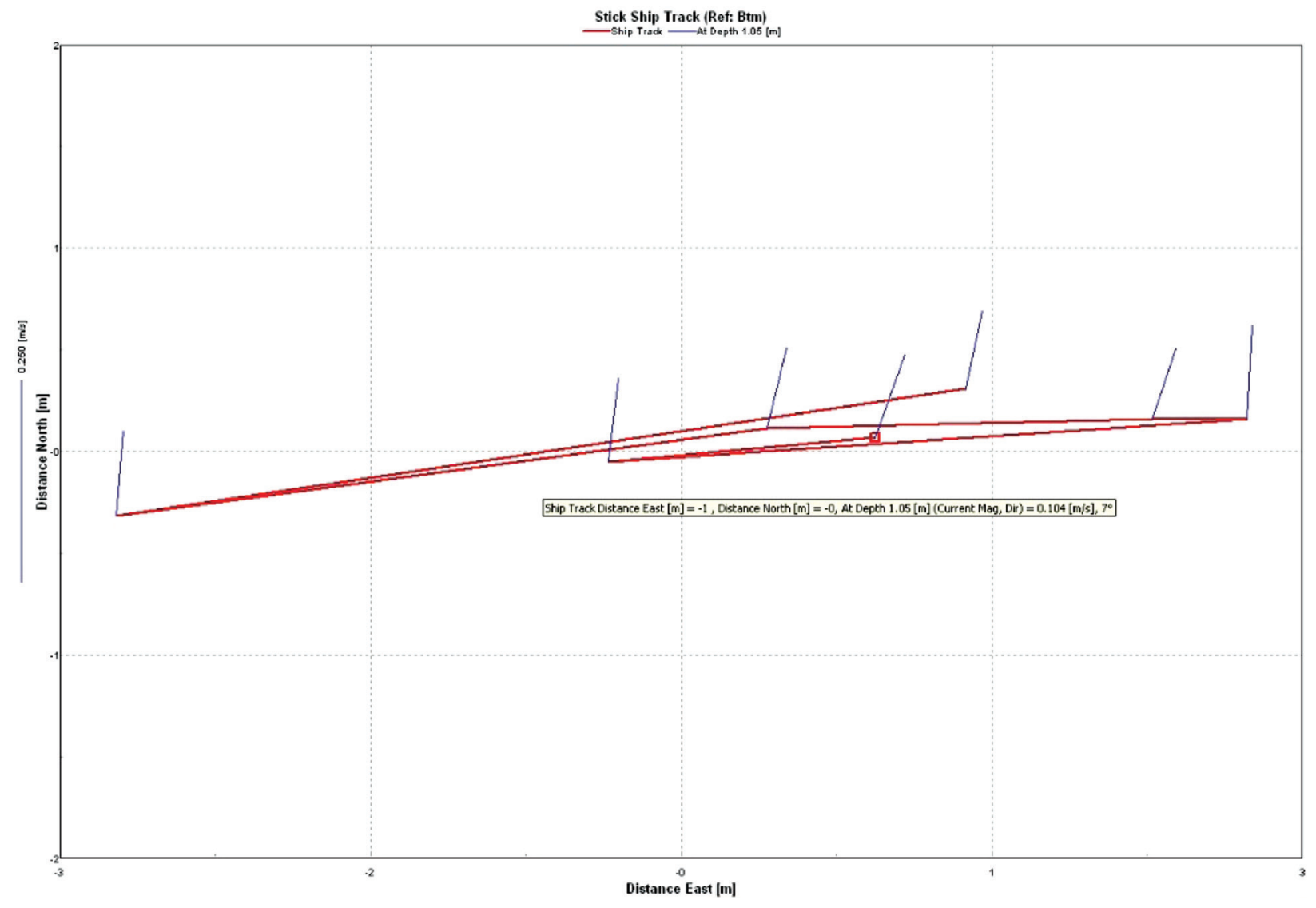

Figure 2. Velocity and direction of the current at a depth of $1 \mathrm{~m}$ in the area of the experiment according to ADCP data. The blue lines represent the current vectors; the red line is the drift trajectory of the scientific boat "Geophysicist" at anchor.

A stripe slick structure formed by a bubble stream was registered on the radar images (figure $3 a, b)$. The dark vertical stripes in figure $3 \mathrm{a}, \mathrm{b}$ are slick spots stretched out in the wind. They have different widths and contrasts: the presence of natural or so-called "background" slicks in the experiment zone allowed us to compare them with an artificial bubble-made slick and to highlight some of the features of the latter. First, this is the difference in contrast (the ratio of the intensity of the radar signal in slicks and on a clean surface) in the background slick and in the bubble-made one, which makes it possible to detect it using radar methods. Secondly, there are morphological differences: slick created by bubble stream has a clearly defined "head" at the place of its formation, i.e. in the area of the bubble stream exit from the water, and it has clearer boundaries in general.

The size of the slick according to visual estimates (figure 3c, d) was $15-20 \mathrm{~m}$ across the wind, and more than $100 \mathrm{~m}$ along the wind. In the upwind of the bubble outlet area a rip was formed, because of the collision of currents initiated by the bubble stream with the wind current. The rip can be seen both on the photographs taken at the initial moment of bubble stream formation (figure 3c) and on the radar images (figure $3 a, b)$.

It should be noted that the natural limitation of the proposed approach is the need of small-scale wind waves on the water surface, which are generated at near-water wind speeds exceeding $2-3 \mathrm{~m} / \mathrm{s}$. But if the wind is too strong (more than $10-12 \mathrm{~m} / \mathrm{s}$ ), the formed slicks will quickly collapse, this fact will also make it difficult to detect such slicks by radar [11]. Further development of the proposed approach requires additional experiments under various hydrometeorological conditions. 
(a)
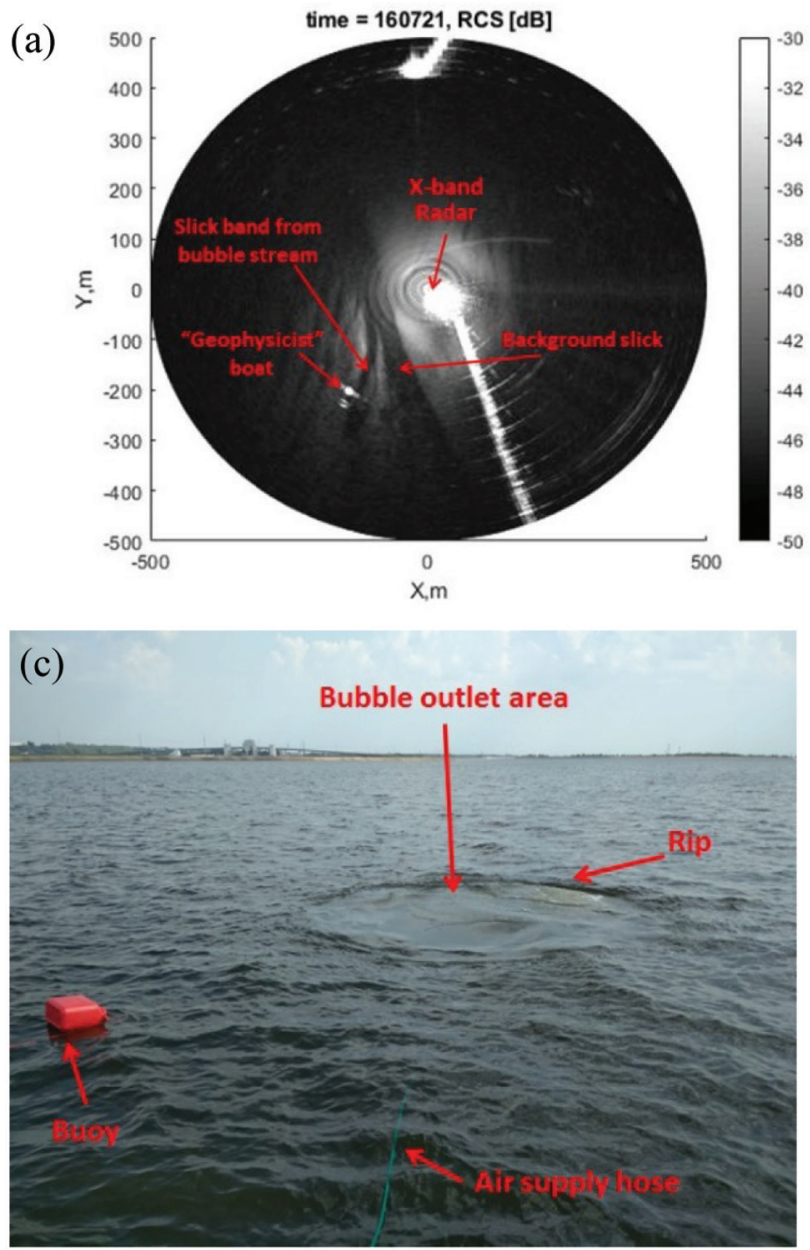
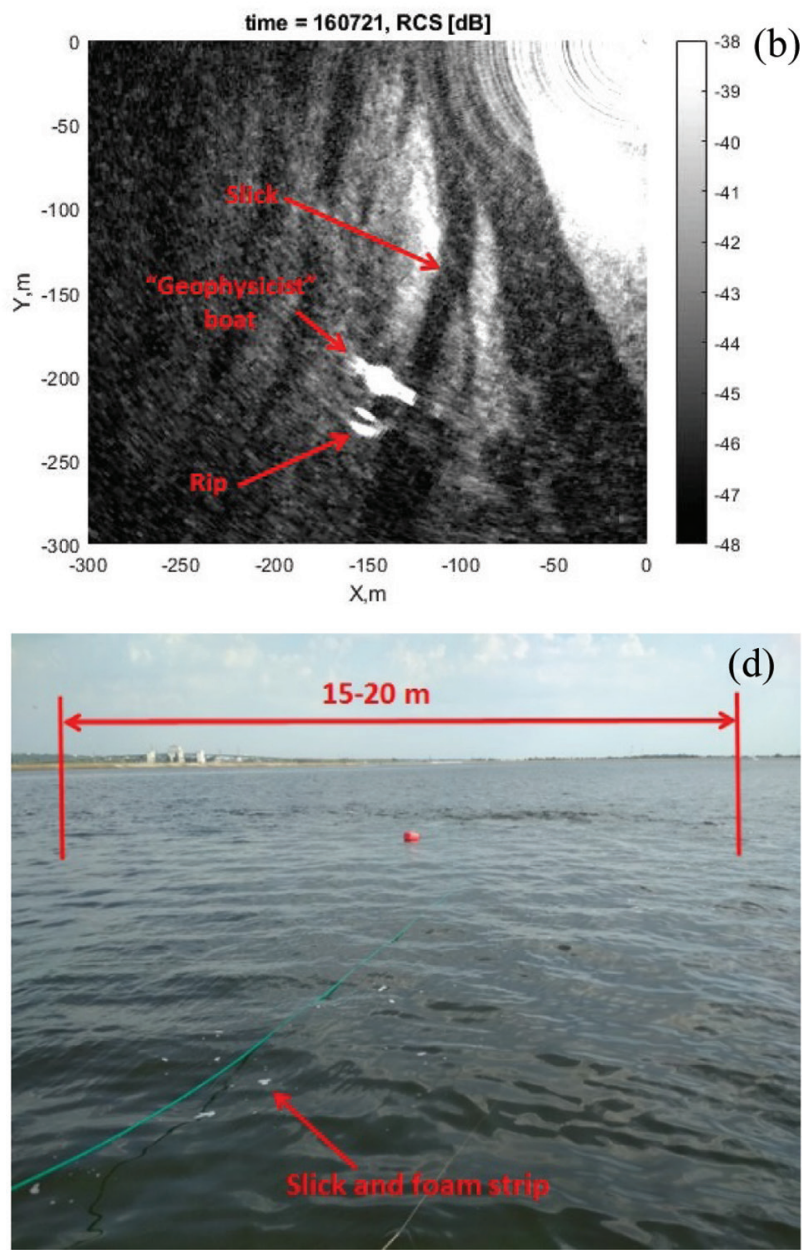

Figure 3. Images of the bubble outlet area: (a) radar image of the water surface in the study area; (b) a fragment of a radar image of a slick formed by the bubble stream; (c) the image of the bubble outlet area at the initial moment of its formation; (d) the image of the bubble outlet area in steady state of the bubble stream.

To create an algorithm for recognizing artificial slicks, including those formed by underwater gas emissions in the field of background slicks, a special polarizing parameter RND (relative Resonant to Nonresonant signal Damping) can be used as a basis, which makes it possible to differentiate various types of film contamination of the sea surface on radar images [21, 22].

\section{Conclusions}

The fact of formation of a film slick on the water surface near the gas outlet area has been confirmed in the field experiment. The surfactants carried by bubble stream to the water surface form a slick spot that can be registered by X-band radar. The size of the slick band obtained in the field experiment was several tens of meters wide and several hundred meters long, this fact opens up opportunities for confident detection of gas outlet areas on the water surface by modern satellite radar methods.

One of the important practical results of this work is the confirmation of the possibility of remote detection of bubble emissions, for example, from damaged of underwater gas pipelines, based on images of slicks above them.

An important distinctive feature of a slick formed by an underwater bubble stream is the difference between its contrast and the contrast of background slicks on radar images. In addition, the bubblemade slick has a clearly defined "head" at the place of its formation and it has clearer boundaries in general.

The proposed approach requires the presence of short wind waves on the water surface and can be effective in the range of near-water wind speeds of $2-12 \mathrm{~m} / \mathrm{s}$. Further development of the approach implies additional experiments under various hydrometeorological conditions. 


\section{Acknowledgements}

This research was carried at the expense of the State task 0729-2020-0037.

\section{References}

[1] Lambrecht A., Maier E., Pernau H.-F., Strahl T., Herbst J., Gas Leak Detection by Dilution of Atmospheric Oxygen, Sensors, 2017, Vol. 17(12), 2804, 14 p., DOI: 10.3390/s17122804.

[2] Shakhova N., Semiletov I., Methane release and coastal environment in the East Siberian Arctic shelf, $J$. Marine Systems, 2007, Vol. 66(1-4), pp. 227-243.

[3] Shakhova N., Semiletov I., Sergienko V., Lobkovsky L., Yusupov V., Salyuk A., Salomatin A., Chernykh D., Kosmach D., Panteleev G., Nicolsky D., Samarkin V., Joye S., Charkin A., Dudarev O., Meluzov A., Gustafsson O., The East Siberian Arctic Shelf: towards further assessment of permafrost-related methane fluxes and role of sea ice, Philosophical Transactions of the Royal Society B, 2015, Vol. 373(2052), 20140451.

[4] Gawarkiewicz G., Korotaev G., Stanichny S., Repetin L., Soloviev D., Synoptic upwelling and crossshelf transport processes along the Crimean coast of the Black Sea, Continental Shelf Research, 1999, Vol. 19(8), pp. 977-1005, DOI: 10.1016/S0278-4343(99)00003-5.

[5] Zhao J., Meng J., Zhang H., Wang S., Sensors, Comprehensive Detection of Gas Plumes from Multibeam Water Column Images with Minimisation of Noise Interferences, 2017, Vol. 17(12), 2755, DOI: 10.3390/ s17122755.

[6] Bulatov M.G., Kravtsov Yu.A., Raev M.D., Repina I.A., Skvortsov E. I., Microwave, optical and IR combined studies of the sea surface perturbations caused by underwater gas bubble plume, IEEE Intern. Geoscience and Remote Sensing Symp. (IGARSS), 2002, Vol. 5, pp. 2983-2985, DOI: 10.1109/ IGARSS.2002.1026843.

[7] Bondur V.G., Kuznetsova T.V., Vorobiev V.E., Zamshin V.V., Remote sensing detection of gas shows (gas seeps) on the Russian shelf, Georesources. Geoenergetics. Geopolitics, 2014, Vol. 1(9), 23 p., available at: http://oilgasjournal.ru/vol_9/bondur.html.

[8] Klassen V.I., Mokrousov V.A.A, An Introduction to the Theory of Flotation, J. Leja, G.W. Poling (Eng. transl.), London: Butterworths, 1963.

[9] Flotation Technology: Handbook of Environmental Engineering, Wang L. K., Shammas N. K., Selke W.A., Aulenbach D. B. (eds.), 2010, Vol. 12, 18 p., DOI: 10.1007/978-1-60327-133-2.

[10] Ermakov S.A., Kapustin I.A., Lazareva T.N., Kalimulin R.R., Sovremennye problemy distantsionnogo zondirovaniya Zemli iz kosmosa, 2013, Vol. 10(4), pp. 298-307.

[11] Ermakov S.A., Influence of films on the dynamics of gravitational-capillary waves, Nizhniy Novgorod: IPF RAN, 2010, $164 \mathrm{p}$.

[12] Smirnova M.V., Kapustin I. A., Glukhova V.S., Nosova A. D., Experimental study of mean and pulsation velocities of flows formed by pop-up bubble flow in a near-surface water layer in the presence of a surfactant film, Vestnik VGAVT, 2019, Vol. 60, pp. 104-112.

[13] Smirnova M. V., Kapustin I.A., Glukhova V.S., Nosova A. D., Lazareva T. N., Formation of a surfactant film around the gas bubbles outlet area on the water surface, Materials of the Volga Basin Ecology Conf. Volga-2019, 2019, Vol. 2, 27, 3 p.

[14] Smirnova M.V., Kapustin I. A., On possibility of remote detection of gas leaks from underwater pipelines using specific slick signatures, Remote Sensing of the Ocean, Sea Ice, Coastal Waters, and Large Water Regions, Proc. SPIE, 2019, Vol. 11150, 111501U.

[15] Miegebielle V., Dubucq D., Taillandier C., Angeliaume S., Use of Remote Sensing Radar Techniques for Oil and Gas O\&G Facilities Survey in Offshore Domain for Environment and Exploration: Oil Slicks Detection and Interpretation Seeps and Spill, SPE Health, Safety, Security, Environment, and Social Responsibility Conference - North America, 2017, DOI: 10.2118/184419-ms.

[16] Lavrova O. Yu., Mityagina M. I., Satellite Monitoring of Surface Film Pollution of the Black Sea, Izvestiya, Atmospheric and Oceanic Physics, 2011, Vol. 3, pp. 48-65.

[17] Ermakov S.A., Resonance Damping of Gravity-Capillary Waves on the Water Surface Covered with a Surface-Active Film, Izvestiya, Atmospheric and Oceanic Physics, 2003, Vol. 39(5), pp. 691-696.

[18] Brekke C., Solberg A., Oil spill detection by satellite remote sensing, Remote Sensing of Environment, 2005, Vol. 5, 1-13.

[19] Lavrova O., Bocharova T., Kostianoy A., Satellite Radar Imagery of the coastal zone: Slicks and Oil Spills, Global Developments in Environmental Earth Observation from Space A. Marcal (ed.), Rotterdam, Netherlands: Millpress, 2006, pp 763-772.

[20] Mityagina M.I., Lavrova O. Yu., Bocharova T.Yu., Sovremennye problemy distantsionnogo zondirovaniya Zemli iz kosmosa, 2016, Vol. 12(5), pp. 130-149.

[21] Ivonin D. V., Skrunes S., Brekke C., Ivanov A.Y., Interpreting sea surface slicks on the basis of the normalized radar cross-section model using Radarsat-2 copolarization dual-channel SAR images, Geophysical Research Letters, 2016, Vol. 43(6), pp. 2748-2757, DOI: 10.1002/2016GL068282. 
[22] Ivonin D. V., Ivanov A. Y., On classification of sea surface oil films using TerraSAR-X satellite polarization data, Oceanology, 2017, Vol. 57(5), pp. 738-750, DOI: 10.7868/S003015741705015X.

[23] Bayramov E., Bayramov R., Aliyeva S., Optical and Radar Remote Sensing and Contamination Probability Modelling for the Advanced Quantitative Risk Assessment of Marine Petroleum and Gas Industry, IFAC-PapersOnLine, 2018, Vol. 51(30), pp. 31-33, DOI: 10.1016/j.ifacol.2018.11.

[24] Krestenitis M., Orfanidis G., Ioannidis K., Avgerinakis K., Vrochidis S., Kompatsiaris I., Oil Spill Identification from Satellite Images Using Deep Neural Networks, Remote Sensing, 2019, Vol. 11, 1762 , DOI: $10.3390 /$ rs11151762.

[25] Kapustin I.A., Shomina O. V., Ermoshkin A. V., Bogatov N.A., Kupaev A. V., Molkov A.A., Ermakov S.A., On Capabilities of Tracking Marine Surface Currents Using Artificial Film Slicks, Remote Sensing, Vol. 11, 840, DOI: 10.3390/rs11070840.

[26] Shomina O.V., Kapustin I.A., Ermoshkin A. V., Ermakov S.A., Sovremennye problemy distantsionnogo zondirovaniya Zemli iz kosmosa, 2019, Vol. 16(4), pp. 222-232, DOI: 10.21046/2070-7401-2019-16-4-222-232. 